\title{
Delivering on sustainable development
}

\author{
The UN General Assembly will meet later this month at the UN headquarters in New York to adopt a political \\ declaration pledging to accelerate efforts to meet the Sustainable Development Goals by 2030.
}

S ince the Sustainable Development Goals (SDGs) were launched in 2015 by the United Nations (UN), and adopted by all member states, a significant number of initiatives have taken place at national and international levels. Overall, the commitment is to contribute to a plan of action for people, planet and prosperity, named the 2030 Agenda for Sustainable Development. As a result, sustainable development is now a buzz term within policy domains, and national governments, to various extents, have engaged with the SDGs and promoted action to achieve the goals by 2030 . Researchers have also stepped up effort to provide the kind of evidence needed to inform the policy interventions required to make progress with the 2030 Agenda. After an initial phase of engagement with the agenda, efforts have also been made to track progress towards the SDGs on a regular basis. The High-level Political Forum (HLPF) - the body responsible for the effective implementation of the 2030 Agenda, including representatives from all of the UN member states - under the auspices of the UN General Assembly, meets annually to review progress towards the goals. In an Editorial from last year, Nature Sustainability reflected on the 2018 SDG Index and Dashboard Report presented at the annual meeting of the forum in July. The message then was dire, as no country seemed on track to achieve all SDGs by 2030 .

This year the works of the forum include new developments. In particular, an independent group of scientists (IGS) appointed by former UN Secretary-General Ban Ki-moon in December 2016 will officially present, during the first SDG Summit to be held at the UN Headquarters in New York later this month, the Global Sustainable Development Report (GSDR) the first report of its kind. The negotiations among UN member states and other groups involved with the annual review of the HLPF started this year in the middle of May, continued at the annual HLPF meeting in July, and will culminate at the SDG Summit with the adoption of a political declaration. Nature Sustainability learned that a preliminary version of the GSDR had already been made available to the negotiators during the deliberations in the lead up to the SDG Summit. In an

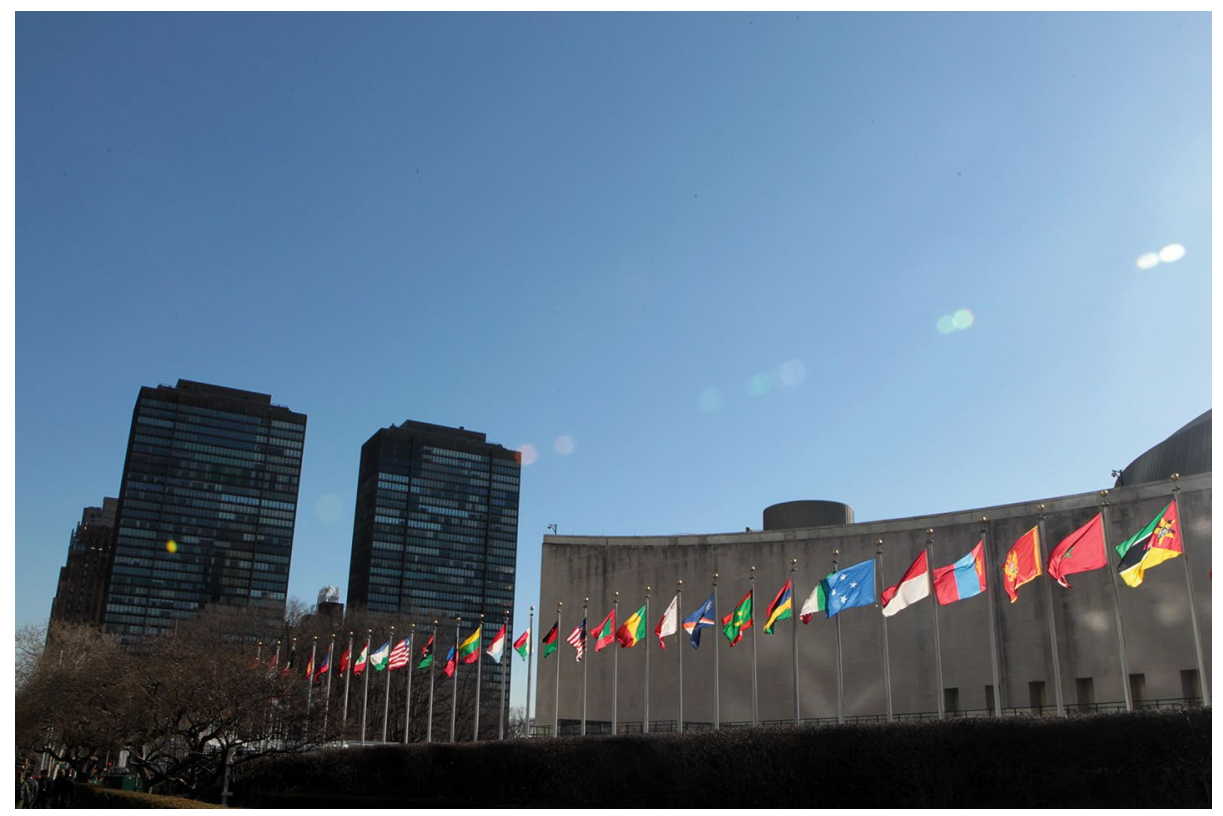

Credit: MediaPunch Inc / Alamy Stock Photo

interview published in July, the IGS co-chair Peter Messerli and IGS member Eeva Furman highlighted the motivation and background work behind the report, its novelty compared to other sustainable-development assessments previously published, and the main goal of the report. Mandated by the UN to the IGS, the report will be published every four years. Messerli defined the report as an assessment of assessments. Apparently, the idea was to draw insights from the many relevant international scientific assessments and UN flagship reports in the public domain, and synthesize all of the assessed evidence into a single document. Despite the wealth of knowledge available to inform the implementation of the 2030 Agenda, the report clearly suggests, as emphasized by Furman, that the state of the science-policy-society interface at present is inadequate to strengthen the contribution of academic research to sustainable development.

The eight-page concept note for the SDG Summit published on 18 July clearly states that the six themes to be addressed during the summit are inspired by the 2019 GSDR. The themes are defined as: (1) megatrends impacting the achievement of the SDGs; (2) accelerating the achievement of the SDGs; (3) leveraging progress across the SDGs; (4) localizing the SDGs; (5) partnership for sustainable development; (6) 2020-2030 vision.

Unsurprisingly, in relation to accelerating the achievement of the SDGs, the GSDR emphasizes the strategic importance of strengthening human well-being, shifting to sustainable economies, building sustainable food systems and the like. All of this is hardly news to scholars and practitioners within the sustainable-development domain. Yet, we value such a synthesis effort aimed at consolidating knowledge and delivering it to decision makers.

We certainly await the official release of the GSDR with enthusiasm. And we definitely agree that action to meet the SDGs needs to accelerate, as we are only a decade away from the target year. But success will depend on the political will to embrace change at all scales, something governments have only occasionally achieved so far. Let us hope that they finally surprise us all.

Published online: 11 September 2019 https://doi.org/10.1038/s41893-019-0386-Z 